\title{
In Theory
}

\author{
What Hat Do I Wear Now?: \\ An Examination of Agency Roles \\ in Collaborative Processes
}

\section{Julia M. Wondolleck and Clare M. Ryan}

\begin{abstract}
As collaborative approaches to resolving public disputes become more prevalent, agency officials are finding themselves in unfamiliar terrain. This article offers one conceptualization of agency roles in collaborative processes, drawing from the experiences of natural resource managers and environmental regulators at the federal level. Based on an examination of 65 cases, the authors identify three distinct "bats" that effective agency officials wear in collaborative processes - leader, partner, and stakebolder. The objective and function of each role is assessed, along with the implications of agency facilitation. The most successful agency representatives were able to blend the three primary roles, and did not act as facilitators of the collaborative process.
\end{abstract}

F well over a decade now, federal, state, and local officials in the United States have been urged to embrace collaborative approaches to decision making. The Administrative Dispute Resolution Act of 1990 (P.L. 101-552) grants federal agencies the authority to use mediation, arbitration, and other consensus-seeking methods in resolving public disputes. Similarly, the Negotiated Rulemaking Act of 1990 (P.L. 101-648) sanctions and clarifies agency use of negotiation in the rule-making process. Indeed, negotiated rulemaking and collaborative decision making have been consistent themes in the Clin-

Julia M. Wondolleck is associate professor of resource policy at the University of Michigan's School of Natural Resources and Environment, 430 E. University, Ann Arbor, Mich. 48109-1115. Clare M. Ryan is assistant professor of natural resources and conflict management at the University of Washington's College of Forest Resources, 123H Anderson Hall, Box 352100, Seattle, Wash. 98195-2100. 
ton Administration's efforts towards reinventing government (Gore 1995). At the state and local community level, legislation has been signed into law that promotes negotiation and collaboration in siting disputes and land use planning (for example, see Bingham and Miller 1987; Innes 1992; Rabe 1994). While not without its critics (Coglianese 1997; McCloskey 1996), this relatively rapid redefinition of approach to administrative decision making in the face of divergent yet legitimate public interests represents a fundamental change in the way agency officials conduct their business as, indeed, it was intended to be.

Agency participants in collaborative processes at all levels of government, however, are struggling to define what this new paradigm implies for them. What is their role in a consensus-based process that engages agency decision makers in face-to-face dialogue and negotiation with nonagency groups and individuals having a stake in the decision to be made? In general, agency representatives hope that, by working collaboratively with stakeholders before decisions are made or policies are adopted, more complete information will inform the policymaker (Ozawa 1991; Yaffee and Wondolleck 1995). Furthermore, mutual understanding of the issues at stake will be fostered, as will communication and trust between the parties involved (Carpenter and Kennedy 1988; Wondolleck 1988). Hence, acceptable decisions will result rather than decisions that are contested in lengthy judicial or administrative appeals processes (Bingham 1986; Susskind and Cruikshank 1987).

But how should agency participants in collaborative negotiation processes juggle the reality that they are the ultimate decision-making authority with the consensus-seeking premise of the collaborative interaction? After decades of being cast in a comfortable role - where expectations were clear, procedures were well-defined, and decisions were sufficiently cloaked in the mantle of agency expertise and professional judgment - the tide has now turned upon these decision makers. What additional "hats" are now needed in their procedural wardrobe in order to be effective in a collaborative context that dramatically differs from their role and context of old?

The role of agency participants in collaborative public dispute resolution processes is a source of confusion to many. While many agency officials are open to the idea of collaboration and negotiated dispute resolution and are willing to pursue a collaborative process, they express uncertainty about precisely how they are to proceed. Multi-party collaborative processes are fundamentally different from most long-established and well-understood standard operating procedures. As one USDA Forest Service official observed, the process is "a kind of awkward dance that none of us know the steps to." A U.S. Fish and Wildlife Service participant in a dispute resolution process recalled: "I didn't know what I was doing. Collaborative problem solving is a different approach than the regulatory two-by-four to the side of

118 Wondolleck and Ryan What Hat Do I Wear Now? 
the head, and it takes a different mindset." Similarly, an Environmental Protection Agency (EPA) participant in a negotiated rulemaking process commented: "I don't think there's a big future for it unless we can learn to do it a lot better. I've found that we are not trained as effective negotiators; we are trained as engineers, as regulators. We have been trained to say 'you do it this way'."

The confusion about agency roles and responsibilities in public sector negotiation is understandable; collaboration among diverse stakeholders is a new way of doing business for public officials. While many agencies have been slow to accommodate or encourage collaborative approaches to decision making and many long-standing institutional structures and administrative procedures impose formidable barriers, there have nonetheless been individuals in some agencies who have been staking out this new terrain, providing useful insights for those who follow in their footsteps. Their experiences shed light on the unique position of agency participants in collaborative processes, and the specific behaviors and approaches that can promote their effectiveness.

\section{Agency Roles in Collaborative Processes: Three Studies}

This article presents one conceptualization of agency roles in collaborative processes, drawing from the experiences of natural resource managers and environmental regulators at the federal level. This conceptual framework is based on a synthesis of the findings of three different studies analyzing the behaviors and reflections of agency and nonagency participants in 65 wideranging collaborative processes. Through interviews and surveys of the multiple parties involved in these processes, the studies examined the roles adopted both successfully and unsuccessfully by agency participants. The agency participants who were effective in these processes were those who were able to meet agency interests and objectives while also satisfying the core interests of the other participants. Decisions emerging from processes with effective agency participants were better informed, better understood, better accepted and better able to be implemented. We asked the question: What roles did agency participants adopt in order to achieve these outcomes? The conceptualization proposed here captures the overarching distinctions observed in these studies. It is not meant to define narrowly or otherwise constrain agency behavior, but rather to begin providing a simple imagery (often in the words of the participants themselves) that might help ease the transition to this new mode of decision making, and increase the effectiveness of those agency individuals who choose to follow a collaborative path. It also suggests an area rich in possibilities for more systematic research into the nuances, implications and particular challenges of each role, the transition between these roles, and their application in different issue contexts. 
The first study was a post hoc assessment of the use of multi-party negotiations to resolve administrative appeals received in the USDA Forest Service's national forest planning process. While the National Forest Management Act of 1976 (P.L. 94-588) was intended, in Senator Hubert H. Humphrey's words, "to get the practice of forestry out of the courts and back to the forests," the agency nonetheless received well over 1,000 administrative appeals on the first round of 135 plans (Wondolleck 1988). Multi-party negotiations were used to resolve the issues under appeal in twenty national forest plans. These were textbook-model negotiations, following the steps generally prescribed by practitioners and scholars of alternative dispute resolution (see Bacow and Wheeler 1985; Bingham 1986; Carpenter and Kennedy 1988; Susskind and Cruikshank 1987). The issues and parties were well-defined and the disputes had reached the point where they were amenable to resolution. Several were mediated by professionals in dispute resolution (Wondolleck 1996). These twenty ADR processes were new to the participating Forest Service employees and the extent, focus and nature of their participation varied case-by-case.

The second study examined 40 collaborative resource management processes undertaken by the USDA Forest Service, U.S. Fish and Wildlife Service and U.S. Bureau of Land Management. Unlike the forest planning negotiations of the first study, these collaborative processes were initiated proactively, before a protracted dispute had arisen yet still in situations where divergent interests were expressing concern about emerging problems. These collaborative negotiations can best be described as having evolved organically, without benefit of the expertise or assistance of a dispute resolution professional. They were ad hoc, open, and ongoing. In fact, many continue today, five years or more after having been initiated (Wondolleck and Yaffee 1994).

The third study evaluated negotiated rulemaking at the U.S. Environmental Protection Agency (EPA), another proactive application of ADR principles. Because traditional rule-making procedures at EPA had become so adversarial and litigious, the agency initiated a regulatory negotiation pilot program in 1984 that incorporated dispute resolution techniques into its decision-making processes, with the goal of using negotiation to reach consensus on the text of selected proposed rules (Harter 1982; Susskind and McMahon 1985). The study examined five cases of negotiated rulemaking that had successfully reached agreement, had not been litigated, and whose agreements had been published as final agency rules (Ryan 1996).

Each of these processes required that agency participants adopt new and different roles. In fact, the processes represented new terrain for most participants, agency and nonagency alike. Some participants recognized the fundamentally different nature of the processes and responded accordingly while others adopted a more limited and traditional view that, in the end, constrained their effectiveness. 
The experiences of agency participants in these different settings suggest a new conception of agency behavior and administrative roles in an era of collaborative decision making, one merging the distinct yet essential roles of leader, partner and stakeholder. Agency representatives who participated in a peripheral manner (for example, serving solely in an oversight capacity or providing only technical data and expertise) were far less effective in guiding the process to a mutually acceptable and implementable agreement. Furthermore, and contrary to conventional wisdom, the facilitator hat was not found to be an appropriate piece of the agency representative's wardrobe and, when worn, was often at significant cost.

\section{The Agency Participant as Leader}

There is an extensive literature on leadership, rich with ideas about leadership in groups, organizations, and in particular, teams (for example, see: Bennis 1985 and 1989; Bennis and Nanus 1985; DePree 1989 and 1992; Drucker 1996; Heifetz 1994; Katzenbach 1998; Kayser 1994; Kouzes and Posner 1987; Terry 1993). Yet, even with the number of volumes on leadership available, few speak directly to leadership in public agencies, and even fewer to agency roles in an increasingly collaborative world (Chrislip and Larson 1994). This oversight is unfortunate given that leader was a central yet seldom acknowledged role of agency participants in the collaborative processes studied. Agency participants in the three studies often confused their expertise or authority with leadership; consequently, they failed to recognize when leadership in the process was lacking and, moreover, their unique responsibility for filling this vacuum. Just as a rudderless boat will shift course with changing winds, seldom reaching its intended destination, so too a leaderless collaborative process will experience difficulty in achieving its intended objective of agreement among the diverse parties.

While it is true that many parties within a collaborative process can and do provide leadership at times, the leadership of the agency participant is fundamentally different and more central to the process because of their distinct decision-making authority. The agency is the party that provides the opportunity for negotiations to occur in a meaningful manner; moreover, the agency's presence and authority gives legitimacy to the collaborative process. In many cases, agency representatives provided critical leadership simply by initiating the process. And by so doing, they set the stage for their continued leadership role. Even in those cases where agencies were not the initial convenor, they nonetheless legitimized the deliberations and eventual outcomes when they made the choice to step into an emerging dialogue. Additionally, because the collaborative approach tends to be a new one for all parties involved, the agency participant is the one that is most often looked to for guidance and frequently must lead by their example. In the contexts of the three studies, leadership was either provided, or clearly needed, in three different realms: first, leadership about the process; second, 
leadership about the issues under discussion; and, finally, leadership about the decisions to be made.

In all three studies, the agency participant took steps that were essential to the initiation, functioning, and progression of the process of the negotiation. As the sponsor, the agency assumed responsibility for all of the logistical steps that started the process and kept it going: hiring a facilitator, arranging for participants to be involved and keeping them at the table once the negotiations or dialogues were underway. They sometimes arranged for meeting space and, in the EPA case, provided travel money for participants as needed. The negotiated rulemaking cases were the most formalized of those studied, with the EPA providing negotiation training for participants to help them participate more effectively, training that was seldom available to participants in the other cases. The timeline for negotiations was usually set by the agency participant; sometimes legally mandated or court-ordered deadlines to develop regulations or complete plans bounded the negotiation. Once the negotiations began, process leadership kept the parties committed and communicating. It was in the agency's interest to provide a structure that motivated participants and encouraged progress toward agreement. As one nonagency participant in an EPA negotiated rulemaking case commented: "Well, they made the whole thing happen, and they were going to accomplish what they were trying to do, which was make a rule."

Providing leadership to the process also involved setting the tone for the interactions, one that was respectful and hopeful. Effective agency participants established high standards of communication, deliberation, openmindedness, commitment, and hard work. As an environmental group participant in a national forest plan negotiation commented, "The supervisor and staff set an excellent tone for reaching good agreements. There was clear delineation of Forest Service obligations and mandates and respect among all participants." In other words, the nature of the agency's participation was such that an atmosphere of credibility and trust in the discussions was established.

Effective agency participants not only provided support and direction to the functioning of the process; they also framed the discussion by setting bounds around the reach and nature of the issues on the table. For example, EPA participants undertook considerable preliminary analysis at the outset of the negotiated rulemaking processes in selecting which specific issues or regulations were appropriate for negotiation. At times, the actual statute, a court decision, administrative appeal, or lawsuit determined the issues to be discussed. Agency participants were often called upon to provide a vision for the group, or encouraged and assisted the group in jointly developing a common vision, problem statement, or guiding objective.

While all parties to the negotiations and discussions shared responsibility for ensuring that all key issues were raised, understood and addressed, the agency participant's leadership fostered this understanding and behavior.

122 Wondolleck and Ryan What Hat Do I Wear Now? 
For example, EPA participants sent issue papers out in advance of the negotiations, devised "straw-man" alternative solutions, and provided data weeks in advance, giving parties the opportunity to discuss specific issues with their constituencies and develop responses and suggestions before meetings. By so doing, the EPA enabled the other participants to engage more effectively in the issues under discussion. Effective agency participants highlighted the opportunities within the issues under discussion, providing pathways out of impasses. Additionally, effective agency participants took the initiative to introduce new issues, resources or parties, or encouraged the other participants to do so, in order to move the process forward.

As a leader, the agency participant also ensured that issues were presented and discussed in a forthright and accurate manner. As an industry representative to an EPA negotiated rulemaking process commented, "the agency has to play a solid role in confirmation of the data." He acknowledged his own attempt to distort the data and issues on the table in his favor and the EPA participant's role in averting this behavior:

Industry can overwhelm the whole process with data presentation and skew it. And if the agency doesn't step forward and say that's unacceptable and we simply won't accept that way of analyzing it, the environmentalists cannot bring that to the table. In this case, the agency did step forward, and they made it very clear what they would and would not accept, and we tried to do a lot of different things and we got stopped.

Ultimately, the agency participant in a collaborative process also provided leadership about the decisions reached during the negotiations. While they instilled a sense of shared responsibility for the issues under discussion by virtue of their adoption of a collaborative approach, effective agency representatives also shouldered additional responsibility at the decision stage. As an environmental participant in an EPA negotiated rule-making process noted, "the agency has to signal something about the outcome." At times, the responsibility fell to the agency participant to make difficult choices and many did so in an upfront and credible manner. Moreover, their visible commitment to the process gave meaning to these decisions and assured the other participants that essential agency follow through would occur.

\section{The Agency Participant as Partner}

A partner is someone who shares a problem, interest, or opportunity in common with other individuals or groups. The cooperative, problem-solving dimension of a collaborative process provides the focus for parties to engage as partners in the effort. Being a partner implies being willing to work together in order to solve a shared problem or pursue a common vision. Partners help others when they need help, and are willing to be helped as needed. They are open-minded and flexible in approach, willing to listen, and able to teach and be taught. They are respectful of other perspectives or, 
as one U.S. Bureau of Land Management official put it, different "ways of knowing." They recognize the value of the contributions made by other participants. In short, partners recognize the "we" component of the problem and potential solution, and act accordingly (Kouzes and Posner 1987).

There are many reasons why agency participants in collaborative negotiations should view themselves as partners (Yaffee and Wondolleck 1996); their interests and knowledge provide but one piece to completion of a larger puzzle. In a time of diminishing resources, they need the help and assistance, the ideas, energies, skills, and resources of others. Unlike earlier times in history, information and knowledge on many issues are widely distributed among governmental and nongovernmental organizations alike, and agencies need to work collaboratively in order to make informed decisions. Together with its partners in the problem-solving component of the collaborative process, the agency can accomplish considerably more than it can working alone.

Being a partner was a uniquely challenging role for agency participants in the collaborative processes studied as it was the role that was least consistent with traditional agency procedures. Consequently, numerous barriers were posed by the perceptions, stereotypes and expectations of participants both from within the agency as well as from the other participating groups. As a U.S. Fish and Wildlife Service participant in one process noted: "One of the first things we had to do was to let each of us be our own experts."

Effective agency participants recognized the need to enter into the process with an open mind and flexibility that was quite at odds with how they customarily made decisions. As the U.S. Fish and Wildlife Service participant commented: "The first meeting was pretty intense. I found out a lot of things that I thought I knew but didn't." Additionally, he observed that another "major difficulty, especially for a biologist, was saying you don't know when you don't know." Over the years, many agency officials have become comfortable in their role as technical experts, the people who know the right answer. Long-standing paradigms and practices provided significant psychological and procedural barriers to adopting a partner role. Furthermore, agency participants were not accustomed to perceiving nonagency groups and individuals as sharing a set of concerns or objectives in common with the agency or viewing them as partners in the decision-making endeavor.

However, encouraging an understanding and adoption by all participants of a partner role was often critical to the ultimate decision. One EPA official illuminated this dimension of the process in describing the contribution of an industry participant:

They made a heck of a contribution to this thing when they walked in one day and out of the blue said "hey, we're willing to control [X]." Those devices were not even part of the discussion; nobody was even thinking about them or talking about them. Yet, they pointed out that if we control 
these, then we would actually get more emissions reductions from the process than we are from controlling all the rest of the damn thing. So that was put on the table by industry and was very effective. . . It was an amazing thing to us.

One of the challenges encountered by agency participants who engaged in the process as partners was that they became a part of something new, a new group with its own identity and objectives to which all parties were committed. Consequently, some participants felt isolated, at times even estranged from their agency "constituents." One U.S. Bureau of Land Management participant commented: "For [agency] people who haven't participated, it's different. They just don't get it." A U.S. Fish and Wildlife Service participant in another case concurred:

\begin{abstract}
When you find a common ground, it really doesn't look quite like what everybody thought it was going to look like. And so it's difficult. You find yourself being a little bit lonely. When I went back to my bosses at the Fish and Wildlife Service, at first their typical response was, "Well, you must have sold out or you have done something horrible because they are all agreeing with you. And those are enemy people, you know. . . there is no way you could have come to an agreement without selling out."
\end{abstract}

There was sort of a group bonding. You get to the point where you have gone out on a limb enough, trying to convince people that this thing is worth doing, that it might work. And then all of a sudden you realize you are kind of out by yourself. You are with this group, not your traditional group. You have a fear of failure. So I think you do some things that are a little riskier. And once you get hammered by your own group, you tend to come back and either you are going to bail out at that point, and stay with the same group that you're comfortable with, or you are going to come back to our group and be more dedicated - and more convinced that you bave to solve this thing because your credibility is hanging out there, and your reputation.

While agency participants are accustomed to being "in charge" and consequently the leader hat is quite compatible with existing norms and procedures, the partner role can be particularly challenging to agency participants and threatening to their agencies. The more an agency participant becomes a partner in this new group, the greater the fear and potential for co-optation. This situation exhibits many characteristics of the negotiator's dilemma (Lax and Sebenius 1986) between creating (a partner's primary focus) and claiming (a stakeholder's primary focus) behaviors. To bridge these roles effectively, the agency participant cannot lose sight of their own organization's interests. They must maintain a level of communication back to others in the agency, keeping them informed of evolving discussions and emerging agreements, ensuring that agency interests are being met and that agency commitment to the process and its outcomes will be forthcoming. 
Sometimes being an effective partner required strong leadership, guiding the other, nonagency parties into a collaborative mode and helping them to recognize that they, too, were a partner and shared responsibility for solving a mutual problem. For example, the facilitator in one national forest plan appeals negotiation process characterized the approach of the lead Forest Service representative at the table by saying:

He would say "quit telling the Forest Service what to do. Get in here and roll up your sleeves and [help us to] do it." And he took a lot of flak for that because [some agency staff thought that] only the Forest Service has skills to write the plan, maintain trails, etc. So he had to fight internally to make this happen.

Thus, the partner role involved not only convincing agency counterparts of the necessity for a partnership perspective but also opening the eyes of the other parties at the table to this dimension of the process and their role and responsibility in it.

Helping others to act as partners required that agency participants break through barriers formed by the expectations, stereotypes and adversarial relationships that were derived from historical interactions between the parties and traditional procedures. As one agency participant commented:

It's hard to negotiate with someone if they think you're a policeman, if they think you are going to use everything they say against them.

Sometimes in the cases we studied, the leader hat did, in fact, slip back onto effective agency participants as they were trying to guide the group along in a manner consistent with their new relationship as partners. The tension between leadership and partnership was a challenge felt by many agency participants in the collaborative processes. One Forest Service participant noted that being a leader does not necessarily mean being "in control" and, in order to encourage a partner relationship, may require relinquishing control at times. He advised:

Whenever possible [do not] take a leadership role that would oust other people. But, if you get into a leadership role, it should be one that enables others to play with you. Most agency personnel have a tendency to. . . want to have full control over it.

Recognizing and helping others to recognize this unique aspect of their new relationship, one that is often in sharp contrast to how they have historically viewed and interacted with each other, was a challenging but important component of the partner role. 


\section{The Agency Participant as Stakebolder}

What is a stakeholder in a collaborative negotiation context? In contrast to partners who acknowledge the "we" dimension of the relationship, a stakeholder recognizes the "me" component of the problem and solution. Effective stakeholders are clear about their own interests, how these interests are similar to or different from those of the other stakeholders, and who within the organization can effectively articulate these interests and persuasively advocate on their behalf. Moreover, stakeholders understand their priorities within these interests and where tradeoffs might acceptably be made. Stakeholders are prepared, ready with persuasive information, data and other resources that can help educate and influence others so that their own interests will be acted upon (Fisher, Ury, and Patton 1991; Lewicki et al. 1994).

Just as the nonagency participants around the negotiating table are stakeholders representing a specific set of organizational interests, so too are the agency representatives in these processes (Yaffee 1994). Agency participants must be aware of the interests and responsibilities that are unique to them as the agency representative at the table, and how these differ from those of the other parties involved. In addition to providing the forum and opportunity and encouraging a cooperative approach to solving shared problems, the agency participant has a particular set of interests to advocate, ensuring that they are accommodated in any agreements that are reached. Some of these interests are derived from the agency's guardian responsibility for broader public interests, including those of future generations, nonhuman species, public health, and ecosystem and environmental integrity. Others are rooted in the laws and regulations governing the agency as well as the other organizational and professional stakes that might be related directly, or perhaps tangentially, to the specific issues on the table. The agency participant wants decisions that can be defended within the agency as well as within the broader political sphere. Perhaps the greatest failing of agency participants in the three collaborative contexts studied here was their lack of preparation and action in recognition of this stakeholder role.

To be effective stakeholders, agency participants must be clear about their range of interests and positions before entering the negotiations. As one Forest Service participant reflected:

\footnotetext{
We need to get our own heads straight on where we think we're going and get our homework done, so we have something in mind. I think we wear people out when we go out and say, "How do you think we ought to do this?"
}

Effective agency stakeholders knew their interests and the priorities within these interests but, at the same time, understood the need to be flexible when pursuing them; they were firm about their objectives but flexible 
about the means for achieving these objectives (Fisher, Ury, and Patton 1991). As one Forest Service participant advised:

Be really flexible in implementing your vision. We had our grand idea on how it ought to work. But as we proceeded down the road, it became apparent that the more people got involved or threatened or interested or interfaced with us, the planning team, we realized that for this thing to succeed, we needed to give here and give there and compromise over there. And we ended up changing some basic program operating fundamentals, where I know my tendency would have been to say, "Hey man, leave me alone. I know what I'm doing." But by listening and changing and tinkering, not losing sight of the vision but not wanting to lose the opportunity to do this at all, our flexibility helped us to be very successful.

This flexibility gave strength to the agency stakeholder and was derived from a solid understanding of the range of agency interests and priorities, and where there was latitude within them. It came from adequate preparation before the negotiation process on the stakeholder dimensions of the agency's role at the table.

In the negotiated rulemaking cases, the EPA's interests were usually defined by agency participants as achieving a rule that complied with the statute and could be promulgated without litigation. Effective EPA participants interpreted the statute for the other parties in order to illustrate the agency's specific interests. They were also open to new ideas and approaches for accomplishing statutory requirements. An industry participant described EPA's stakeholder role as both effective and appropriate:

EPA had a position. They weren't just calling balls and strikes, and everybody - the industry, states, and environmentalists - had to realize that they were dealing with an agency that was determined and willing to promulgate a regulation.

Acting as a stakeholder signaled to the other participants that the agency was serious about the issues, and was not going to sit back and let others direct the eventual decision. In so doing, however, they also needed to be aware that strong stakeholder behavior by the agency could be construed by others as "strong arming" of the process. Balancing the role of leader with that of stakeholder can be tricky as well as confusing to the other participants if the agency is not transparent about what "hat" they are wearing as the process evolves.

\section{Agency Representatives versus Agency Facilitators}

What little attention has been given in the literature to the specific question of agency role has most often focused on facilitation (Carpenter and Kennedy 1988; Shannon 1992). Some have argued that agencies should serve as the "facilitator of a community of interests" (Sirmon et al. 1993) or "referee" (Goergen et al. 1997) when working collaboratively with diverse 
stakeholders in a public dispute. They suggest that agency participants should help the other participants to resolve their differences. We have found these characterizations to be both limiting and misleading, making agency officials less effective than they might be otherwise. Many collaborative processes do indeed need a facilitator to assist the parties in effective communication, negotiation, and problem solving. Many individuals can fulfill this role, including an agency official. But the agency facilitator should not be the same agency official who is responsible for representing the agency's interests at the table. In all three studies, we found that combined agency facilitation and representation proved not only ineffective but counterproductive to the consensus-seeking objective of the process.

One reason that it is counterproductive to have an agency representative also serve as facilitator is perceptual; a facilitator is perceived to be removed from the issues under discussion and with a set of responsibilities and objectives that are different from those of the other parties at the table. In other words, the facilitator is perceived to have no substantive stake in the proceedings. However, most participants in the three studies felt quite strongly that the agency does indeed have a stake in the deliberations and should actively advocate its interests as a stakeholder just as the other participants were doing. When the agency representative adopted the role of facilitator, the other participants felt that the agency was not sincere in its involvement in the process and was shirking its larger responsibilities to be an environmental guardian or steward. An industry participant in an EPA regulatory negotiation commented: "When EPA facilitates, we feel like EPA is really ducking their responsibility." An environmental group participant concurred: "There is some element of EPA abdicating their responsibilities, and the parties can't let EPA do that."

Although agency participants will invariably at times serve some of the functions of a facilitator, almost every participant in these studies agreed that the agency must act as more than simply a process facilitator. Many felt that having a separate, independent facilitator provided the necessary impetus that encouraged the agency representative to participate on a par with the other parties. As one Forest Service participant noted:

Having an independent party to run the process - really facilitating all of these plans - was a key factor for success. It's not the Forest Service directly that's leading the meetings. We're all in the same boat because there's someone else standing in front of the room saying "okay, here's what we're dealing with today."

It is important to note, however, that these findings do not automatically lead to the conclusion that an agency official should never wear a facilitator's hat in a collaborative process. In fact, three of the national forest planning appeals negotiations involved agency facilitators who were effective in this role as well as respected by all involved parties, agency and 
nonagency alike. They were all individuals who had acquired previous training in mediation and facilitation and hence were skilled at these functions. But an important distinction must be made about the involvement of these agency facilitators. All three were either not from the forests involved in the appeals or were not representing these forests. In other words, the Forest Service facilitators in these three cases were not also parties to the negotiations; they were not the agency's representative at the table. These two roles are undeniably linked, and it can be difficult to separate them, particularly in the eyes of nonagency participants.

The experiences of agency participants in these three studies highlight the reality that participating in a collaborative process is a significantly different task from assisting with a process. One finding was quite clear: the agency representative to a collaborative process should not also serve as its facilitator; the two hats are simply not compatible.

\section{The Three Hats in a Collaborative Wardrobe}

The wardrobe of many public policymakers and administrators today contains three new hats, suggesting three specific roles that need to be performed as these individuals seek to fulfill their responsibilities within a collaborative context. These roles are not seamlessly merged into one but instead must be consciously balanced and performed as appropriate. Agency officials are still experts; they still have specific authorities; and they are still the decision makers. But in order to fulfill their responsibilities, act upon their expertise, and uphold their legislative mandates in an effective manner, they must also become a leader of, partner with, and stakeholder among the diverse interests of society in making the difficult public choices represented by their decisions. The three studies discussed here did not reveal any magical formula dictating which hat should be worn when, with what aplomb and how transitions between roles might best be finessed. Nonetheless, the studies do suggest a new conception of agency roles that should help agency participants better understand the range of variation in their responsibilities and be better attuned to the evolving dynamics of a process that is new to most parties involved and particularly challenging for agency representatives to it.

As Watkins and Winters (1996) noted, roles are socially constructed, grounded in the beliefs and expectations of the disputants. Agency participants must be cognizant of the perceptions of the other parties at the table, and clarify their roles as they evolve. In the conceptualization of agency roles proposed in this article, agency participants must transition between roles in a transparent manner so that motives are not questioned nor actions misinterpreted. As Watkins and Winters (1996: 128) found in their study of variation in mediator roles, "the ability to challenge the constraints imposed by role definitions and to shift others' perceptions of one's role is an important element of leadership in intervention." These studies suggest that the 
same is true for leadership in agency participation, given the unique status and authority of the agency representative at the table.

The experiences of agency officials who have participated in collaborative interactions are enlightening for those still struggling or about to embark on a collaborative endeavor. The idea of collaboration is a promising one (see Gray 1989), but that promise can only be realized if agency officials participate with an accurate understanding of the process, its objectives and functioning, and an understanding of their varied roles in it. The three studies illustrated vividly that how an agency participates in a collaborative process and with what effect is a direct function of why they have chosen to participate in the first place. And why they choose to participate and hence how they prepare, perceive what is going on, and participate in the process is, in turn, a direct function of their level of understanding, or lack thereof, of the nature and potential of the collaborative process (Wondolleck 1996).

Effective agency participants in the situations discussed here were not experts in collaboration and did not always adopt these roles with ease. As one Forest Service participant in a highly successful negotiation lamented, "I had little or no experience and I was heavily involved; I had no training, did a lot of groping, made mistakes. . . . it wasn't pretty." Regardless, those who were most effective recognized the need to follow a new path, and acknowledged when they had never before traversed it. Their honesty, sincerity and openness was motivating and acceptable to the other parties at the table.

Those who were effective in the three studies discussed here balanced these three essential roles. They understood that the agency had a stake in the proceedings and prepared accordingly. They advocated the agency's interests in the deliberations. In other words, they were a stakeholder both in the context of the dispute and the negotiation process. Those who were effective also recognized that the problem being tackled was one that all involved shared and consequently needed to work together to find a solution. They acknowledged the "we" component of the problem and its eventual solution. In other words, they were a partner. Finally, those who were effective also realized that, regardless of being a stakeholder and a partner, they were still the decision maker. They were still the convenor of the process and the authority in charge. When the other participants looked to them for guidance, direction and, at times, decisions, effective agency participants were ready and responsive. In other words, they were the leader of the process. They appreciated the fundamentally different nature of the collaborative process and their need to proceed with a new perspective and in a different manner than that dictated by traditional agency procedures. 


\section{NOTE}

1. Unless otherwise noted, all direct quotations in this article referring to cases involving the USDA Forest Service, U.S. Bureau of Land Management, or U.S. Fish and Wildlife Service, are extracted from cases in Wondolleck and Yaffee (forthcoming). All quotes referring to U.S. Environmental Protection Agency negotiated rulemaking cases are extracted from Ryan (1996).

\section{REFERENCES}

Bacow, L. S. and M. Wheeler. 1985. Environmental dispute resolution. New York: Plenum.

Bennis, W. 1985. On becoming a leader. Reading, Mass.: Addison Wesley.

- - - 1989. Why leaders can't lead. San Francisco: Jossey-Bass.

Bennis, W. and B. Nanus. 1985. Leaders. New York: HarperCollins.

Bingham, G. A. 1986. Resolving environmental disputes: A decade of experience. Washington: The Conservation Foundation.

Bingham, G. and D. S. Miller. 1987. Prospects for resolving hazardous waste siting disputes through negotiations. Natural Resource Lawyer. 18(3): 473-489.

Carpenter, S. L. and W.J.D. Kennedy. 1988. Managing public disputes: A practical guide to handling conflict and reaching agreements. San Francisco: Jossey-Bass.

Chrislip, D. D. and C. E. Larson. 1994. Collaborative leadership: How citizens and civic leaders can make a difference. San Francisco: Jossey-Bass.

Coglianese, C. 1997. Assessing consensus: The promise and performance of negotiated rulemaking. Duke Law Journal. 46(4): 1255-1349.

DePree, M. 1989. Leadership is an art. New York: Dell.

- - . 1992. Leadership jazz. New York: Dell.

Drucker, P.F. 1996. The executive in action. New York: HarperCollins.

Fisher, R., W. Ury, and B. Patton. 1991. Getting to YES: Negotiating agreement without giving in. 2nd ed. New York: Penguin.

Goergen, M. T., D.W. Floyd, and P.G. Ashton. 1997. An old model for building consensus and a new role for foresters. Journal of Forestry 95(1): 8-12.

Gore, A. 1995. Common sense government: Works better and costs less. New York: Random House.

Gray, B. 1989. Collaborating: Finding common ground for multiparty problems. San Francisco: Jossey-Bass.

Harter, P. J. 1982. Negotiating regulations: A cure for the malaise? Georgetown Law Journal 71(1): $1-118$

Heifetz, R.A. 1994. Leadership without easy answers. Cambridge, Mass.: Belknap/Harvard.

Innes, J.E. 1992. Group processes and the social construction of growth management: Florida, Vermont, and New Jersey. Journal of the American Planning Association 58(4): 440-54.

Katzenbach, J.R. 1998. Teams at the top. Boston: Harvard Business School Press.

Kayser, T.A. 1994. Building team power: How to unleash the collaborative genius of work teams. Homewood, Ill.: Irwin.

Kouzes, J. and B. Posner. 1987. The leadership challenge: How to get extraordinary things done in organizations. San Francisco: Jossey-Bass.

Lax, D. and J. K. Sebenius. 1986. The manager as negotiator. New York: The Free Press.

Lewicki, R. J., J.A. Litterer, J.W. Minton and D.M. Saunders. 1994. Negotiation. 2nd ed. Burr Ridge, Ill.: Irwin

McCloskey, M. 1996. The skeptic: Collaboration has its limits. High Country News 28(9): 7.

Ozawa, C. 1991. Recasting science: Consensual procedures in public policy making. Boulder, Colo.: Westview.

Rabe, B. 1994. Beyond NIMBY: Hazardous waste siting in Canada and the United States. Washington: Brookings.

Ryan, C.M. 1996. Leadership in regulatory negotiations at the Environmental Protection Agency: An analysis of roles. Unpublished doctoral dissertation. The University of Michigan, School of Natural Resources and Environment.

Shannon, M. A. 1992. Foresters as strategic thinkers, facilitators, and citizens. Journal of Forestry 90(10): 24-27.

Sirmon, J., W.E. Shands, and C. Liggett. 1993. Communities of interests and open decisionmaking. Washington: Pinchot Institute for Conservation. 
Susskind, L. and J. Cruikshank. 1987. Breaking the impasse: Consensual approaches to resolving public disputes. New York: Basic Books.

Susskind, L. and G. McMahon. 1985. The theory and practice of negotiated rulemaking. Yale Journal of Regulation 3(1): 133-165

Susskind, L., E.F. Babbitt and P.N. Segal. 1993. When ADR becomes the law: A review of federal practice. Negotiation Journal 9(1): 59-75.

Terry, R.W. 1993. Authentic leadership: Courage in action. San Francisco: Jossey-Bass.

Watkins, M. and K. Winters. 1997. Intervenors with interests and power. Negotiation Journal. 13(2): 119-142.

Wondolleck, J. M. 1988. Public lands conflict and resolution: Managing national forest disputes. New York: Plenum.

- - - 1996. The long-term consequences of using negotiation to resolve national forest planning disputes. Paper presented at the Sixth International Symposium on Society and Resource Management, Pennsylvania State University, State College, Penn. 22 May 1996.

Wondolleck, J.M. and S.L. Yaffee. 1994. Building bridges across agency boundaries: In search of excellence in the United States Forest Service. A research report to the USDA Forest Service, Pacific Northwest Research Station. Ann Arbor: School of Natural Resources and Environment. The University of Michigan.

- - - and - - . Forthcoming. Building bridges: Creating partnership and resolving conflict for a sustainable future. Washington: Island Press.

Yaffee, S.L. 1994. The wisdom of the spotted owl: Policy lessons for a new century. Washington: Island Press.

Yaffee, S.L. and J.M. Wondolleck. 1995. Building knowledge pools and relationsheds. Journal of Forestry 92(5): 60.

- - - and - - . 1996. Building bridges across agency boundaries. In Creating a forestry for the twenty-first century: The science of ecosystem management, edited by $\mathrm{K}$. Kohm and $\mathrm{J}$. F. Franklin. Washington: Island Press. 